\title{
ECONOMIA COMPORTAMENTAL APLICADA A POLÍTICAS
} PÚBLICAS: UM EXERCíCIO ANALÍTICO SOBRE A LEI 13.656/2018 E O INCENTIVO À DOAÇÃO DE MEDULA ÓSSEA NO BRASIL

\author{
Behavioral Economics Applied to Public Policies: An Analytical Exercise \\ on Law 13.656/2018 and the Incentive to Bone Marrow Donation In Brazil
}

\author{
Yuri Dantas \\ Universidade Federal da Bahia, Salvador-BA, Brasil \\ ygcdantas@gmail.com
}

\begin{abstract}
RESUMO
O objetivo deste trabalho é mostrar a possibilidade da aplicação da economia comportamental como catalizadora de resultados em uma política pública. Primeiramente, é preciso mostrar a existência da racionalidade limitada que pode interferir no processo de escolha dos indivíduos. Ademais, é importante legitimar as interferências governamentais que visem a correção de comportamentos sem o uso da coerção. Como estudo de caso, será utilizado o quadro de doação de medula óssea no Brasil. Após a aprovação da lei 13.656/2018, que concede isenção de pagamento da taxa de inscrição de concursos públicos para os cadastrados como doadores de medula, há uma possibilidade de aumento do cadastramento, mas não da doação efetiva. Dado que a recusa pode ser fatal ao paciente à espera do transplante, será importante a formulação de políticas públicas que promovam o cadastramento consciente, sendo os conhecimentos desenvolvidos pela teoria comportamental um candidato viável.
\end{abstract}

PALAVRAS-CHAVE: Economia Comportamental. Economia da Saúde. Altruísmo.

\begin{abstract}
The objective of this paper is to show the possibility of applying behavioral economics as a catalyst for results in public policy. First, it is necessary to show the existence of a bounded rationality that can interfere in the choosing process. In addition, it is important to legitimize governmental interferences aimed at correcting behaviors, showing how behavioral economics can soften them without coercion. As a case study, bone's marrow donation in Brazil framework will be used. After the approval of the law 13.656/2018, which grants exemption from payment of the public tenders' registration fee for those registered as bone marrow donors, there is the possibility of increasing the registration, but not the effective donation. Since the refusal can be fatal for a patient waiting for a transplant, it'll be important to formulate public policies that aim to encourage conscious registration, and the knowledge developed by behavioral theory may be a viable candidate.
\end{abstract}

KEYWORDS: Behavioral Economics. Health Economics. Altruism

Classificação JEL: D03. I18. D64

Recebido em: 25-03-2021. Aceito em: 05-01-2022. 


\section{INTRODUÇÃO}

O modo como as políticas públicas devem ser abordadas não é unânime no campo teórico. Segundo a escola econômica de Chicago, a racionalidade humana é mais que suficiente, sendo desnecessário, e até imoral, o uso de meios que intervenham nas escolhas das pessoas, a menos que essas escolhas sejam danosas a outrem (KAHNEMAN, 2012, p. 514). Já, segundo a economia comportamental, as pessoas precisam de auxílio para melhorar a capacidade de julgamento e tomada de decisões, sendo as políticas públicas a maneira mais adequada para tal (ibidem).

Assim, o presente trabalho se propõe a apresentar a abordagem da economia comportamental sobre as políticas públicas, com destaque na área da saúde. Como defendido pela teoria, um governo inserido em uma realidade que apresenta seres humanos imperfeitos, imediatistas e impulsivos não deve se portar de maneira negligente. Como estudo de caso, será abordada a questão da doação de medula óssea no Brasil sob a lente da teoria comportamental.

Dessa forma, o problema proposto é o seguinte: considerando as limitações que as políticas públicas na área da saúde enfrentam e atendo-se a se enquadrar como um estudo de caso, é possível que a teoria da economia comportamental se torne um potencial catalisador de resultados? Assim sendo, a hipótese abordada é que a interpretação do problema sob a perspectiva comportamental dá luz aos motivos oriundos da falha humana que o geram, tornando-se um método mais eficaz de desenvolvimento de soluções nas políticas públicas, principalmente quando medidas coercitivas devem ser evitadas.

Para tal, além da introdução e conclusão, este artigo é composto por mais três seções. Na primeira, será traçado um breve apanhado histórico da teoria comportamental, tendo como foco analisar o funcionamento da realidade a partir da desmistificação do homo economicus e de sua racionalidade onisciente, que gera inconsistências no entendimento do comportamento humano efetivo.

Partindo da metodologia empregada pela teoria comportamental, foi possível coletar conhecimentos para a elaboração de técnicas, comumente denominadas de nudge (empurrão), de aproveitamento dos desvios de comportamento por meio do uso de incentivos e não de medidas coercitivas para o beneficiamento da sociedade e/ou neutralização dos malefícios gerados por comportamentos irracionais involuntários. Nesse sentido, na segunda seção, será mostrado a sua aplicação prática comumente conhecida 
como paternalismo libertário, em que o Estado pode se portar de uma maneira paterna (daí paternalismo) ao se preocupar com o bem-estar de seus cidadãos, mas sem tirar a sua autonomia ou capacidade de escolha (daí libertário).

Em seguida, na terceira seção, começaremos o bloco analítico do trabalho, focando o campo das políticas públicas sob a égide da teoria comportamental. O estudo de caso parte da aprovação da Lei 13.656, sancionada em abril de 2018, em que os candidatos de concursos públicos que são cadastrados como doadores de medula óssea terão isenção do pagamento da taxa de inscrição.

Por um lado, a isenção pode ser vista como um incentivo que impulsionaria o cadastro de doação de medula óssea no país. Por outro lado, segundo nota do REDOME - órgão vinculado ao INCA, "o cadastro no REDOME é, por definição, um ato voluntário [...] e este não pode estar vinculado a nenhum tipo de vantagem ou recompensa" (REDOME, 2018). O órgão ainda esclarece que não é somente o número de cadastros que influencia na doação, e sim o seu nível de comprometimento. Dessa forma, a lei pode ser um atrativo para indivíduos que se cadastrem visando somente o benefício, sem que haja comprometimento com a causa.

Por fim, será feita uma análise dos desafios e possíveis agravamentos a serem enfrentados após a Lei 13.656, e como uma interpretação sob a perspectiva da teoria comportamental pode abrir os horizontes no que diz respeito a soluções alternativas propostas por políticas públicas que visem aumentar o nível de comprometimento dos cadastrados como doadores de medula. Destaca-se que o trabalho não se compromete a elaborar estratégias que devam ser efetivamente transformadas em ações estatais, mas é guiado pelo objetivo de identificar e analisar os possíveis impactos da aprovação da Lei 13.656 tanto no cadastramento quanto na doação efetiva de medula óssea, além de discutir medidas políticas em potencial, frisando a teoria comportamental como espinha dorsal.

\section{ECONOMIA COMPORTAMENTAL: TRAJETÓRIA E CONHECIMENTOS}

A economia comportamental sempre esteve presente nos estudos econômicos, só que sem a denominação utilizada atualmente. Por exemplo, segundo ilustrado por Camerer e Loewenstein (2002), no século XVIII, o livro "A Teoria dos Sentimentos Morais" de Adam Smith já utilizava princípios da psicologia - que na época ainda não era reconhecida como uma disciplina - para explicar o comportamento humano no meio econômico. 
Além disso, na década de 1950, o economista Herbet Simon defendeu teorias econômicas voltadas aos comportamentos individuais que incorporavam fatores cognitivos nas análises algorítmicas e cunhou o termo "racionalidade limitada" (bounded rationality) (CAMERER, 1999, p. 10575). No final da década de 1970, elaboraram-se importantes trabalhos para a economia comportamental. Como exemplo, temos a Teoria das Perspectivas (Prospect Theory) de Daniel Kahneman e Amos Tsverky, a qual critica a teoria da utilidade esperada como modelo para expressar a tomada de decisões sob incerteza (KAHNEMAN; TVERSKY, 1979, p. 263). Outro exemplo é o trabalho de Richard Thaler que, além de tratar tópicos sobre contabilidade mental, autocontrole e nudge, aborda também as discrepâncias das teorias econômicas tradicionais que, ao levar em consideração a maximização racional, focam em descrever como os consumidores supostamente escolheriam - mas não como escolhem de fato - sua cesta de bens (THALER, 1979, p. 39).

Mas, afinal de contas, o que seria a economia comportamental? Conforme argumenta Ávila e Bianchi (2015), a economia comportamental é motivada pela crítica à abordagem econômica tradicional do homo economicus, que é o indivíduo atomizado, tomador de decisão racional, ponderado, centrado no interesse pessoal e onisciente (ÁVILA; BIANCHI, 2015, p. 14).

Para superar essas defasagens da visão econômica acerca da realidade, é papel dos economistas comportamentais transformar o homo economicus novamente em homo sapiens. Portanto, a intenção dessa nova perspectiva apresentada pela teoria comportamental está mais orientada no sentido de revisar a teoria econômica e torná-la mais prática e aplicável em situações cotidianas reais e não mais em um cenário axiomático generalizador da atuação dos agentes econômicos.

Nesse sentido, apesar de ser uma tarefa árdua, o processo de escolha pode ser preliminarmente explicado pela teoria comportamental. Para tal, embora os estudos sejam elaborados em diferentes pessoas e em diferentes situações, foca-se na identificação de habilidades cognitivas comuns, seus benefícios e limitações e na obtenção de comportamentos observáveis comuns aos indivíduos (LOWENSTEIN; ANGNER, 2006, p. 28).

Assim, o ponto central de debate na teoria comportamental é a racionalidade dos agentes econômicos. Dessa forma, racionalidade pode ser definida como "uma relação de adequação (eficácia) entre fins pré-estabelecidos e meios para atingi-los" (BARROS, 2010, p. 03). E essa adequação passa por três etapas até sua concretização: 1- listagem dos componentes alternativos possíveis; 2- determinação das consequências provenientes de 
cada componente alternativo; e 3- a comparação das consequências ao se escolher cada componente alternativo (ibidem).

Percebe-se que esse processo necessita satisfazer três pressupostos de acordo com a teoria tradicional do agente econômico racional: 1- o indivíduo deve saber todas as alternativas possíveis; 2- deve conhecer e antecipar todas as alternativas consideradas; 3e o peso das consequências por ele imposto deve ser previsto de forma não imaginária (SIMON, 1987, p. 80-81). Esse processo hipotético onisciente da racionalidade é denominado racionalidade plena.

Entretanto, o mundo real deixa em evidência que o ser humano é incapaz de listar todas as opções possíveis e calcular seus custos e benefícios para então chegar ao estabelecimento de uma escolha. Para tal, faz-se necessário mudar esse ponto de vista generalizador para, então, partir de uma análise real do processo decisório. Portanto, Simon (1976) argumenta que quanto mais a teoria econômica se preocupa com o processo, mais precisará emprestar conhecimentos da psicologia - ou construir por si mesma uma teoria da cognição humana, como o que faz a economia comportamental. E conclui:

Os processos de decisão, como todos os outros aspectos das instituições econômicas, existem dentro da cabeça humana. Eles estão sujeitos a mudanças a cada mudança no conhecimento humano e a cada mudança nas formas de cálculo. Por essa razão, a tentativa de prever e prescrever o comportamento econômico humano por inferência dedutiva a partir de um pequeno conjunto de premissas incontestáveis deve falhar e já falhou. (SIMON, 1976, p. 84-85. Tradução própria)

Contudo, não basta apontar as discrepâncias da teoria tradicional estabelecida, é preciso apresentar uma alternativa com embasamento teórico e evidências (SIMON, 1979, p. 509). E essa mudança na abordagem pode ser feita com o conceito da racionalidade limitada, que é uma racionalidade que "assume que o tomador de decisão precisa procurar por alternativas, tem um conhecimento flagrantemente incompleto e impreciso sobre as consequências das escolhas, e escolhe ações que se espera que sejam satisfatórias" (SIMON, 1997, p. 17). Assim, os tomadores de decisão não buscam comparar todas as opções possíveis em busca da melhor alternativa com o propósito de maximizar seu bemestar, mas sim escolher uma opção satisfatória que atenda seus critérios subjetivos de aceitabilidade. 
Assim, a racionalidade limitada faz com que o resultado de uma situação de escolha seja dependente do processo particular que o gerou, ou seja, o estudo do processo é imprescindível para se entender como as escolhas são feitas (BARROS, 2010, p. 14). Ademais, o entendimento do comportamento humano efetivo, com suas falhas e erros sistemáticos, proporciona uma visão mais realista de um processo de tomada de decisão na prática. Essa nova perspectiva faz com que os economistas e o setor público tenham um contato maior com situações reais de julgamento e saibam de antemão como agir em um cenário de assimetria de informação em que as expectativas e incertezas regem os agentes econômicos. Basicamente, é como dizer que o ator não escolhe aquilo que deseja de maneira integralmente racional e que diversos fatores podem influenciá-lo na decisão, como sua satisfação, cognição, emoção, dentre outros.

Então, em suma, o fator diferencial da tomada de decisão na racionalidade plena para a racionalidade limitada são os atalhos ou simplificações de processamento denominados de heurística: "procedimento simples que ajuda a encontrar respostas adequadas, ainda que geralmente imperfeitas, para perguntas difíceis" (KAHNEMAN, 2012, p. 127). Além disso, fatores externos tais como emoções, pressões sociais e motivações individuais geram vieses cognitivos - erros sistemáticos de processamento e interpretação do redor advindos da aplicação indevida de heurísticas no processo decisório (BAZERMAN; MOORE, 2010, p. 19). Dito de outro modo, o uso sistemático de simplificações e a confiança em seus resultados provocam vieses previsíveis nos julgamentos (KAHNEMAN, 2012, p. 14), que podem ser entendidos como "anomalias" comportamentais. Diante dessa realidade, nada mais condizente do que o aproveitamento mais recorrente desse conhecimento pelos formuladores de políticas públicas.

Portanto, assim como um médico precisa dominar uma ampla gama de classificações das enfermidades para poder associar cada ideia da doença com suas complicações, causas e desdobramentos com o intuito de, então, estudar possíveis intervenções de tratamentos (KAHNEMAN, 2012, p. 09), os formuladores de políticas públicas deveriam investigar as heurísticas e vieses cognitivos, a fim de enriquecer a compreensão acerca dos julgamentos e escolhas dos agentes econômicos. Vale a pena ressaltar que o foco no conhecimento acerca do erro não tem o propósito de rebaixar a inteligência humana, "assim como a atenção com as doenças na literatura médica não significa rejeitar a boa saúde" (ibidem, p. 10).

\section{PATERNALISMO LIBERTÁRIO E A ARQUITETURA DE ESCOLHAS}


Como visto na seção anterior, o ser humano está longe de ser onisciente, onipresente e com a possibilidade de tomada decisões perfeitas. Entretanto, apesar das suas limitações, ele consegue interpretar a situação, adaptar-se e fazer escolhas satisfatórias, e inclusive potencialmente ótimas no ponto de vista maximizador de utilidade. Contudo, o problema surge quando nesse processo há prejuízos de qualquer natureza, tanto para o indivíduo, quanto para terceiros, prejuízos estes que poderiam ser evitados com a ajuda de um espectador ativo - um agente externo que se pressupõe apresentar julgamentos mais corretos que o indivíduo que está em um processo de escolha.

A fim de evitar que tal possibilidade ocorra, é preciso, em primeiro lugar, entender em que circunstâncias e por quais motivos essas ajudas são necessárias. E essa etapa fica mais evidente quando se tem conhecimento de comportamentos humanos que não apresentavam respaldo nas classificações convencionais, isto é, no processo axiomático de escolha da teoria tradicional (ÁVILA; BIANCHI, 2015, p. 15). Com essa nova perspectiva, foi possível respaldar a imprescindibilidade de se analisar os agentes econômicos durante o processo de tomada de decisão como seres humanos falhos e a necessidade de se utilizar "empurrões" para guiá-los no processo.

Portanto, os indivíduos, em muitos domínios, não escolhem de acordo com suas verdadeiras preferências porque não exibem expectativas racionais, falham ao fazer previsões, usam heurísticas que levam a erros sistemáticos e, por conseguinte, têm como resultado escolhas que variam dependendo da forma como são apresentadas, da forma como são interpretadas, das circunstâncias envolvidas e dos valores subjetivos (THALER; SUSTEIN, 2003, p. 03). Tendo em vista essas particularidades que envolvem o processo decisório dos agentes econômicos, pode-se concluir que o comportamento humano apresenta "anomalias" que encorajam escolhas subótimas e que não são totalmente eficientes.

Deste modo, seria positivo o estabelecimento de algum mecanismo de redirecionamento da atenção dos agentes e auxílio no processamento das informações, principalmente quando a tomada de decisão se dá sob circunstâncias adversas e passíveis de influência. Uma vez que muitas das consequências das escolhas irracionais podem gerar efeitos negativos no ponto de vista macro, como problemas de saúde pública e inadimplência, uma saída concreta seria ações dos próprios governos para incentivar comportamentos social e individualmente benéficos.

Portanto, diante do que foi apresentado, uma ferramenta promissora para a compreensão dessas ações governamentais é o "paternalismo libertário". Em linhas gerais, 
o paternalismo libertário é a ideia de que o Estado deve se portar como um pai (ou uma mãe), na medida em que guia o processo de escolha dos cidadãos, mas sem interferir na liberdade para tal. Ou seja, basicamente, é uma maneira de incentivar um comportamento visto como social e individualmente benéfico sem que haja qualquer tipo de coerção ou restrição das opções válidas. Assim, o uso de conceitos da economia comportamental pode guiar o comportamento individual para condutas que tragam benefícios ou simplesmente não tragam malefícios para a sociedade por meio da neutralização de vieses cognitivos.

Contudo, a ideia não é a construção de um Estado que force os cidadãos a terem uma dieta balanceada ou a assistirem apenas a programas de televisão de cunho cultural, mas sim um Estado que possa dar um empurrão nas pessoas para que elas possam tomar decisões condizentes com seus próprios interesses de longo prazo (KAHNEMAN, 2012, p. 516). Portanto, sabendo que as pessoas fazem más escolhas e que precisam de alguma interferência, como proceder? Qual medida deverá ser adotada para corrigi-las e, ao mesmo tempo, não contestar os valores da liberdade e autonomia? Quando se fala em paternalismo, a primeira impressão que temos é que as intervenções governamentais só são possíveis por meio de proibição, regulação e coerção. E, quando se tenta harmonizar valores que são de certa forma contraditórios, como intervir respeitando a liberdade e autonomia, é que a relevância da economia comportamental fica evidente.

Levando em consideração as falhas de julgamento e a racionalidade limitada, há maneiras mais sutis de influenciar no processo decisório dos indivíduos. Como, por exemplo, ao mudar as condições as quais os indivíduos fazem as escolhas, a decisão pode ser influenciada e o impacto na autonomia é supostamente minimizado (GRAND; NEW, 2015, p. 134). Portanto, o estudo do comportamento humano e a análise das falhas de julgamento são imprescindíveis quando se coloca em pauta o direcionamento de escolhas de maneira não coercitiva.

Para tal, é preciso entender que os instrumentos usualmente utilizados pelo Estado são as políticas públicas. A ação governamental, na forma de políticas públicas, apresenta etapas de diagnóstico, formulação e implantação. Contudo, a elaboração de políticas públicas não é um processo ordenado e racional, como a introdução, desenvolvimento e conclusão de um artigo acadêmico (LINDBLOM, 1991, p. 12-13). Por exemplo, a solução de um problema de um determinado grupo pode significar a criação de outro problema para outro grupo distinto; algumas políticas públicas podem ter sido criadas para corrigir as consequências de políticas públicas anteriores, fazendo com que muitas vezes a fase de implantação e elaboração se confundam; e, às vezes, as políticas públicas são criadas 
através do comprometimento dos agentes formuladores, sem que ninguém tenha em mente os reais problemas envolvidos em sua elaboração (ibidem, p. 13).

Quando os agentes formuladores de políticas públicas que presam pela liberdade diagnosticam um comportamento classificado como social ou individualmente prejudicial, eles enfrentam um dilema. Por um lado, o livre-arbítrio defendido tem como consequência simples e natural atribuir mérito e culpa aos indivíduos pelas ações aprovadas e desaprovadas, respectivamente (BAUM, 2005, p. 205). Por outro lado, a ideia do livrearbítrio é comumente atrelada ao uso de medidas coercitivas, punitivas e repressivas para as ações "desaprovadas" (ibidem, p. 206). Todavia, de acordo com Baum (2005), pessoas que prezam pela liberdade reconhecem que a coerção traz, a longo prazo, infelicidade e revolta, defendendo que o direito de escolher livremente tem como alicerce básico a preservação da felicidade das pessoas.

Então, a fim de evitar os efeitos danosos da coerção e, ao mesmo tempo, defender a liberdade das pessoas, deve-se direcionar o holofote para a economia comportamental e aos estudos do comportamento humano. Em primeiro lugar, tem-se em mente que as ações não são inteiramente controladas e planejadas. E, negligenciar a lacuna existente entre a intenção e a ação pode gerar efeitos negativos para os indivíduos e reflexos na sociedade como um todo (DATTA; MULLANAITHAN, 2014, p. 33).

A priori, segundo Datta e Mullanaithan (2014), três ressalvas devem ser feitas quando se planeja utilizar os conhecimentos da economia comportamental em políticas públicas: 1) deve haver motivos para se acreditar que as barreiras comportamentais são as responsáveis pelo desempenho insatisfatório das políticas anteriores; 2) os esforços devem ter como objetivo alcançar impactos em escala; e 3) a inovação deve ser incorporada ao processo de design da política desde o início e ser utilizada durante todo o processo - ou seja, não se devem inserir as inovações em políticas públicas já existentes ou tirá-las das políticas que já estão em vigor (DATTA; MULLANAITHAN, 2014, p. 32).

A partir dessa perspectiva, é necessário especificar as situações em que as pessoas são menos propensas a fazer boas escolhas e elaborar mecanismos, com auxílio dos conhecimentos da economia comportamental, os quais são passíveis de melhorar o desempenho das políticas públicas. Um desses mecanismos, e também conhecida como regra de ouro do paternalismo libertário, é a arquitetura de escolhas (THALER; SUSTEIN, 2008, p. 72). Desse modo, arquitetos de escolha são aqueles que indiretamente influenciam na escolha de outras pessoas. Sabendo que as escolhas dos indivíduos variarão a depender da forma como uma situação é apresentada, como se inicia e qual será 
a opção padrão, o arquiteto de escolhas deverá apresentar um bom entendimento do comportamento humano - e é a partir daí que a importância da economia comportamental é reforçada (ibidem, p. 83).

$\mathrm{O}$ arquiteto de escolhas influencia indiretamente no processo decisório por meio dos nudges ou "empurrões". O nudge é o aspecto da arquitetura de escolhas que altera o comportamento dos indivíduos de maneira previsível, sem proibir as demais opções ou mudar significativamente os incentivos econômicos (THALER; SUSTEIN, 2008, p. 06). Dessa forma, a liberdade e autonomia são respeitadas, e o direcionamento das escolhas não se dá por aliciamento - ou recompensa financeira direta. O nudge deve ser simples e não trazer prejuízo para quem não o aderir; deve ser mais propenso a ajudar e menos a infligir mal; deve ser irrelevante para o homo economicus, mas significativo para o homo sapiens (ibidem, p. 08).

Os críticos da arquitetura de escolhas têm medo da iniciativa se desenvolver em posturas paternalistas mais intrusivas (THALER; SUSTEIN, 2008, p. 236), e defendem que se o governo desejar direcionar o comportamento dos indivíduos, já existem ferramentas disponíveis para tal, como taxação, banimento e subsídios (WHITE, 2013, p. 96). Contudo, Sustein (2015) afirma que os nudges são como um GPS, eles guiam as pessoas na direção correta, mas elas ainda teriam a total liberdade de escolher sua própria rota. Além do mais, em alguns casos, a forma como as opções será organizada é decisiva, e é nesse aspecto que reside a inevitabilidade da arquitetura de escolhas. Diante dessa inevitabilidade, Thaler e Sustein (2008) acrescentam que é justamente por sua natureza não intrusiva que a arquitetura de escolhas salvaguardaria os indivíduos de possíveis desvios de conduta do Estado, como manipulação e abuso de poder.

Um exemplo de política de nudge que não necessita utilizar incentivos econômicos é o uso do status quo. Os indivíduos apresentam um viés de status quo ou opção default, em que muitas vezes preferem deixar as coisas como estão e permanecem inertes em um momento de escolha. Portanto, o arquiteto de escolhas precisa depositar mais atenção na opção padrão, ou seja, a opção que será escolhida caso nada seja feito. A ideia central é organizar uma determinada política para que um conjunto diferente de implicações, que traga benefícios em longo prazo, caia sobre o indivíduo que continua sem fazer nada (GRAND; NEW, 2015, p. 135). Como exemplo, tem-se o sistema de aposentadoria norte americano, denominado 401(k). Madrian e Shea (2000) notaram mudanças significativas no comportamento de poupança dos empregados em grandes empresas dos Estados Unidos quando a inscrição no plano de aposentadoria era feita automaticamente. Os 
envolvidos continuaram possuindo a opção de se desligar do programa, mas muitos permaneceram justamente por inércia.

Outra situação é o modo como as escolhas serão apresentadas para os indivíduos ou o framing (enquadramento) da informação. O governo pode exigir que as informações sejam fornecidas de alguma forma específica, explicitando os riscos e suas probabilidades. A economia comportamental advoga que "as pessoas preferem evitar perdas a ter ganhos de valor equivalente, assim, as políticas públicas devem focar não nos prêmios, mas nas perdas que acontecerão se determinado comportamento não for adotado" (ÁVILA; MENEGUIN, 2015, p. 214). Por exemplo, "um procedimento médico poderia ser descrito em termos da proporção de pessoas com probabilidade de estarem vivas depois de cinco anos, ou à proporção que se espera que esteja morta. As pessoas reagem de maneira diferente a uma probabilidade, dependendo de como ela é descrita, mesmo quando o conteúdo permanece o mesmo" (GRAND; NEW, 2015, p. 136 - Tradução própria). Outro caso são as advertências de saúde com uso de linguagem dissuasiva ou imagens que retratem vividamente os efeitos negativos potenciais (ibidem, p. 137).

Contudo, deve-se ressaltar que os nudges não são receituários (THALER; SUSTEIN, 2008, p. 06). Apesar do sucesso de uma intervenção em um determinado local, é preciso reconhecer que o contexto importa e que não há uma abordagem mágica que concilie as decisões de todos os agentes de maneira padronizada e robótica. Portanto, o que deu certo em um local, com um público-alvo, pode não dar certo em outro (STOICOV, 2014, p. 26). Service et al. (2012) destacam que testes rigorosos e estudos aprofundados da realidade da região em que se pretende aplicar os nudges devem ser realizados a fim de garantir que os formuladores de políticas públicas tenham, e sejam capazes de comprovar, os resultados positivos da aplicação (SERVICE et al., 2012, p. 08).

Em suma, a arquitetura de escolhas e o paternalismo libertário são estratégias viáveis de mudança de comportamento que não utiliza regulação e coerção, e não ataca a liberdade e a autonomia, podendo ser decisiva em situações em que seja necessário alterar o estilo de vida de cada pessoa para que haja resultados significativos - casos em que a proibição será algo impensável. Em linhas gerais, o paternalismo libertário e a arquitetura de escolhas ajudam as pessoas a se ajudarem (GRAND; NEW, 2015, p. 138).

\section{EXERCÍCIO ANALÍTICO SOBRE A LEI 13.656/2018 E O INCENTIVO ECONÔMICO A DOAÇÃO DE MÉDULA ÓSSEA NO BRASIL}


A partir do que foi discutido sobre a teoria comportamental no decorrer deste trabalho, será feito um exercício analítico sobre a Lei 13.656/2018, que isenta do pagamento da taxa de inscrição os candidatos cadastrados como doadores de medula óssea, apresentando como impacto um possível aumento do número de cadastrados, mas que não garante a qualidade - isto é, se os novos cadastrados realmente irão efetuar a doação quando solicitados. Para tal, será apresentado o quadro atual de doação e cadastro de medula óssea no Brasil. A ideia é discutir, por meio de uma análise do comportamento humano, quais as possíveis ações governamentais para melhorar o quadro de doação atual e quais medidas de prevenção poderão ser adotadas para evitar um possível agravamento ocasionado pela lei.

\subsection{Dilema no incentivo econômico à doação}

Seja por meio de campanhas de coleta de roupa e alimentos para os necessitados, ou de trabalho voluntário em causas de caridade ou doação de sangue e medula óssea, a existência do altruísmo não pode ser negada. De acordo com Bernabou e Tirole (2006), "as pessoas geralmente realizam boas ações e se afastam das egoístas por causa da pressão social e das normas que atribuem honra ao primeiro e vergonha ao segundo" (BERNABOU; TIROLE, 2006, p. 1653 - Tradução própria). Por essa razão que há controvérsias quanto à eficácia em se incentivar economicamente doações (como sangue e medula) que são fortemente ligadas ao motivo altruísta. Nessa questão, o incentivo econômico pode atuar como um divisor de águas, no sentido de separar as pessoas que são realmente generosas daquelas que só querem parecer generosas (ELLINGSEN; JOHANNESSON, 2007, p. 01).

Levando em conta a seletividade do doador, dificuldade em se achar doador compatível e a responsabilidade de salvar uma vida, é inquestionável o interessante em incentivar a doação. A dubiedade surge quando se utiliza recompensas econômicas como forma de incentivá-la. Estudos realizados nos EUA por Titmuss (1998) na década de 1960 e Piliavin (1990) na década de 1970 argumentam que o uso de recompensas nas "doações" de sangue, quando há pagamento pelo sangue coletado, reduziria o fornecimento daqueles que anteriormente contribuíam gratuitamente. Ademais, uma revisão bibliográfica executada por Niza et al. (2013) nos bancos de sangue da Suíça, Suécia e EUA no início dos anos 2000 também comprovou a ineficiência dos incentivos, já que não há aumento da quantidade de sangue doado, mas ocasiona a introdução de custos adicionais. $E$ as 
conclusões podem ser estendidas em algum grau para outras ações pró-sociais duplicáveis, que podem ser repetidas, como a doação de medula.

Assim, quando a doação de sangue é paga, o valor intrínseco da doação como sinal de generosidade seria reduzido. A desmotivação daqueles que participavam do ato por motivos altruístas é derivada da forte necessidade dos indivíduos em manter conformidade entre as ações e certos valores, objetivos em longo prazo ou identidades que elas pretendem defender (BERNABOU; TIROLE, 2006, p. 1653). Assim, como muitos doadores eram motivados pela aclamação social ou pela satisfação pessoal de praticar a ação altruísta, a implantação dos incentivos econômicos pode ter sido interpretada como um insulto à dignidade e aos valores defendidos, ocasionando a recusa em praticar a doação (ibidem, p. 1674).

A fim executar uma transfusão segura, é essencial manter padrões rigorosos de seleção de doadores por meio de um levantamento do estado e histórico de saúde e dos hábitos sociais dos mesmos. Entretanto, essa não era a realidade dos bancos de sangue comerciais. Doadores comerciais eram mais prováveis a não só transmitir hepatite póstransfusão, como constatou Titmuss (1998) nos EUA na década de 60, mas também HIV, como constatado em estudos realizados no final da década de 1980 nos EUA (NELSON et al., 1990), México (SEPULVEDA et al., 1988) e Brasil (CARVALHO et al., 1988), principalmente por serem mais suscetíveis ao uso de drogas intravenosas e doar sem se preocupar com seu estado de saúde. Nesse quesito, a "qualidade" da doação voluntária de sangue é maior que a doação de sangue paga. (BEAL E AKEN, 1992, p. 3).

Dessa forma, as tentativas de se mensurar sentimentos subjetivos se mostraram contraproducentes, no sentido de afastar aqueles indivíduos que doavam gratuitamente e, portanto, eram mais motivados por sentimentos intrínsecos de altruísmo - e atrair aqueles que antes não participavam de tais ações. O problema é que, por terem sido atraídos pelo prêmio advindo das doações, os novos indivíduos eram geralmente socialmente vulneráveis e com maior probabilidade de apresentar saúde debilitada e se envolverem em práticas de risco. Não é possível concluir que a ausência do altruísmo foi a razão pela qual a qualidade do sangue doado caiu, mas se constatou que incentivos econômicos podem ferir a dignidade e motivação dos anteriormente envolvidos na atividade.

Apesar da doação de medula óssea ser um procedimento mais difícil, trabalhoso e custoso que a doação de sangue, a essência do ato de doar é muito parecida. $\mathrm{E}$ o uso de recompensas monetárias para incentivar a sua prática pode ser tão pernicioso quanto na 
doação de sangue. No caso da Lei 13.656/2018, a recompensa não é o pagamento direto pela doação, como aconteceu com a doação de sangue, mas sim a isenção de pagamento de taxa de inscrição nos concursos públicos.

A qualificação como incentivo econômico pode ser contestável, já que não há pagamento direto pela medula óssea doada. Entretanto, não se pode negar que é um privilégio concedido a quem se cadastrar como doador e, apesar de ser uma maneira de aumentar a quantidade de cadastrados, não se garante a qualidade. Isto é, dos cadastrados que se registraram e pretendem realmente doar a medula. As consequências podem ser tão contraproducentes quanto as obtidas com o pagamento de sangue. Mas, antes, é preciso entender as particularidades da doação de medula óssea e o quadro de doação de medula no Brasil, como será abordado a seguir.

\subsection{Doação de medula óssea no brasil e a Lei 13.656/2018}

Segundo Bergstrom et al. (2007), achar um doador de medula óssea compatível é exponencialmente mais dificíl do que no caso da doação de sangue. A probabilidade aumenta se os indivíduos forem da mesma etnia. Mesmo assim, enquanto as chances de um doador ser do tipo sanguineo mais raro (O negativo) é de $7 \%$, a probabilidade de correspondência entre duas pessoas da mesma etnia selecionadas aleatoriamente é menor que um em dez mil (BERGSTROM et al., 2007, p. 02).

Ademais, não há tratamento alternativo para o transplante de medula óssea, podendo só haver administrações paliativas como hospitalizações, visitas domiciliares e serviços psicossociais para pacientes com doenças crônicas ou terminais (DURBIN, 1988, p. 776). Por isso, a importância de manter o banco de cadastro de doadores cheio e atualizado, a fim de aumentar as chances de se encontrar compatibilidade entre o doador e o receptor.

Segundo dados disponíveis pelo REDOME (2021a) - Registro Nacional de Doadores Voluntários de Medula Óssea, o número de doadores cadastrados no Brasil atualizado em dezembro de 2020 foi de 5,3 milhões, sendo o terceiro país com maior banco de doadores de medula óssea no mundo (MINISTÉRIO DA SAÚDE, 2020). Mas, vale ressaltar que os indivíduos cadastrados não podem tirar seus registros do REDOME, como tipagem HLA (exame de compatibilidade) e informações de contato, e que os mesmos serão desligados 
automaticamente ao completar 60 anos de idade (ibidem). Assim, é lógico que o número de doadores cadastrados terá uma tendência crescente.

De acordo com informações do REDOME [2021b], quando se procura um doador, a primeira etapa sempre será dentro da família, em geral um irmão, onde a probabilidade de compatibilidade é maior, cerca de $25 \%$. Na ausência no seio familiar, as informações dos receptores cadastrados são cruzadas com o banco de doadores para ver se há alguma correspondência não aparentada. Em média, 850 pacientes estão em busca de um doador não aparentado no Brasil (REDOME, 2021a). O cruzamento de dados é feito todos os dias, daí surge a importância dos doadores em manter os dados cadastrais sempre atualizados.

Apesar de já existir benefícios legais aos doadores de sangue e medula, como a cobertura dos gastos com deslocamento, folga sem desconto no salário para trabalhadores celetistas, precedência ao agendar exames no SUS e direito a descontos de $50 \%$ em ingressos de atividades culturais e de lazer (CEON - CENTRO DE ONCOLOGIA, [2021]), no dia 30 de abril de 2018, o governo brasileiro sancionou a Lei 13.656, que predispõe a insenção de pagamento de taxa de inscrição em concursos públicos "para provimento de cargo efetivo ou emprego permanente em órgãos ou entidades da administração pública direta e indireta de qualquer dos Poderes da União [...] os candidatos doadores de medula óssea em entidades reconhecidas pelo Ministério da Saúde" (BRASIL, 2018).

A comprovação do cadastro deve ser apresentada no momento da inscrição e o candidato que prestar informações falsas com o intuito de usufruir da isenção, estará sujeito ao cancelamento da inscrição e exclusão do concurso; exclusão da lista de aprovados caso a falsidade seja contestada após a homologação do resultado; e nulidade da nomeação caso a falsidade seja comprovada após a publicação (BRASIL, 2018).

Contudo, levando em consideração a impossibilidade de retirada do registro no REDOME e considerando a implementação efetiva da lei em 2018, ao se analisar a variação percentual do número de cadastrados, como consta no Gráfico 01, é possível visualizar que as variações são positivas, mas com taxas decrescentes desde 2015. Além disso, não houve crescimento da variação nos anos 2018-2019. Então, pode-se afirmar que a lei não provocou o efeito esperado; isto é, não houve um aumento significativo do cadastramento após a disponibilização do incentivo.

Gráfico 01 - Variação do Número de Doadores Cadastrados no Brasil: 2008-2020 (\%) 


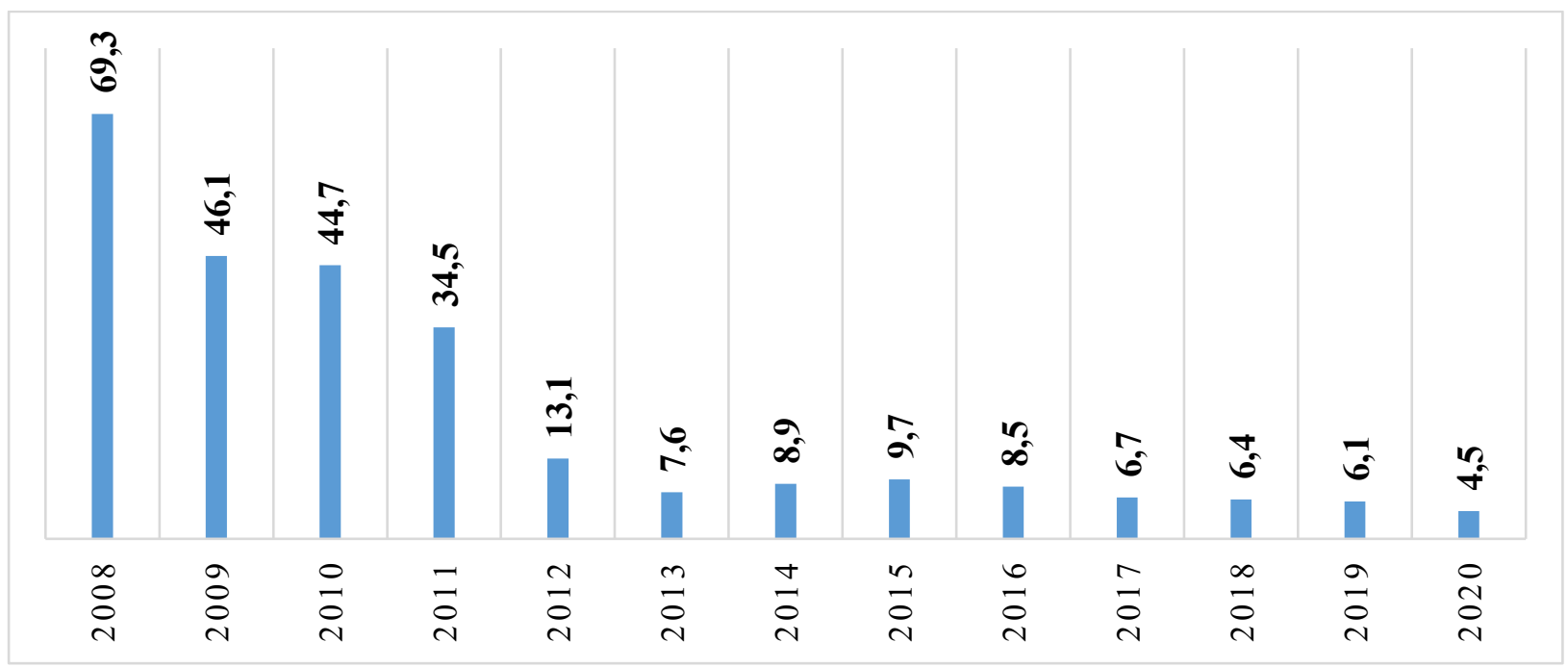

Fonte: REDOME, 2021a. Elaboração própria.

Ademais, a lei não aborda outra realidade: como a doação é voluntária, os cadastrados podem recusar fazê-la quando solicitados, e essa situação é uma realidade preocupante nos centros do Brasil. De acordo com a presidenta da AMEO, Dra. Adriana Seber, a perda de um doador no estágio de confirmação de compatibilidade - último estágio para a doação ser realmente efetuada - é uma catástrofe, pois o paciente a espera pode não resistir e acabar falecendo (VILLAGRA, [2016a]).

Além disso, Wagner Fernandes - gerente da AMEO -, em entrevista a Villagra ([2016b]), ressalta que, além da esperança do paciente e dos familiares que é perdida quando ficam sabendo que um doador foi encontrado e o mesmo desistiu, há desperdício de recursos públicos usados para cadastrar e manter o cadastro das pessoas no REDOME, já que os custeios com a coleta e tipagem HLA são bancados pelo Ministério da Saúde.

Dessa forma, de um modo geral, no caso brasileiro, é possível afirmar que os potenciais motivos da desistência da doação efetiva da medula podem ser: o medo (de agulha, se submeter a procedimentos médicos), desinformação, falta de interesse, apatia, inconveniência, desatualização dos dados cadastrais e mudança no quadro de saúde do cadastrado. Evelyn Guerra, em entrevista a Villagra [2016b], destaca que muitas pessoas se cadastram na euforia do momento, sem comprometimento e responsabilidade em manter os votos a longo prazo. Ademais, a desatualização dos dados é preocupante, muitas vezes a localização é feita por telefone, e-mail ou endereço e, quando o cadastrado passa 10 anos sem atualizá-los, é impossível entrar em contato (VILLAGRA, [2016a]).

Destarte, enquanto a lei incentiva o cadastramento, não há preocupação em efetivamente motivar os cadastrados a realmente doarem quando forem solicitados. A lei 
não foi sancionada por má fé, sendo óbvio que houve empenho e intenções positivas por trás de sua criação para ajudar os pacientes que estão à espera de um doador. Mas, como se posicionou o REDOME [2018], não se pode negar que o cadastro de doador deve ser, sobretudo, uma ação consciente, responsável e espontânea, onde não se deve haver recompensas ou privilégios envolvidos para incentivá-la. Pensando nessa realidade, é preciso desenvolver não só estratégias que atraiam novos cadastrados, como a Lei 13.656, mas também políticas públicas que sejam capazes de motivar a doação quando o cadastrado for contatado. E nesse aspecto a economia comportamental pode impulsionar o cumprimento desse objetivo.

\subsection{Diagnosticando o problema e desenvolvendo soluções alternativas sob a perspectiva comportamental}

Em algum momento da vida, enfrentamos o risco de que nós ou alguém próximo a nós precisará de um transplante de medula. Deste modo, o cadastro de medula óssea pode ser visto como um bem público que aumentará nossas chances de encontrar um doador compatível (BERNSTROM et al, 2007, p. 06). Porém, levando em consideração as informações apresentadas no decorrer deste trabalho, pode-se perceber que a falha da Lei 13.656/2018 é focar somente na atração de novos cadastros para manter o banco de doadores rico e variado, o que não deixa de ser importante, contudo, ela não leva em consideração o real propósito do cadastro: efetuar a doação. De nada adiantaria ter o maior banco de cadastro do mundo se a recusa de doação é elevada.

Bergstrom et al. (2007) argumenta que uma alternativa mais eficiente para o uso de incentivos econômicos na doação de medula é a recompensa para aqueles que realmente fizessem a doação, o que aumentaria a proporção de cadastrados que realmente aceitariam doar. Contudo, no caso analisado, encontrar a compatibilidade entre doador e receptor é algo demorado. O que pode exceder o processo de homologação e efetivação do cargo de concurso público. Ademais, só há penalidade para os indivíduos que forjarem seu cadastro e não para aqueles que recusarem efetuar a doação de medula. Portanto, a lei carece de regulação nesse aspecto.

Assim, tratando-se de doação de medula óssea, é preciso abordar todos os aspectos que envolvem a sua realização: o cadastramento - que, de certa forma, foi tratado pela lei - e a efetuação da doação - que, até então, carece de estratégias. Primeiramente, é preciso 
diagnosticar os motivos que levam os cadastrados a recusarem fazer a doação. Somente após o seu diagnóstico é que é possível desenvolver soluções alternativas, específicas para cada particularidade dos problemas diagnosticados.

Assim, como destacado anteriormente, dentre os potenciais motivos para não se efetivar a doação, quatro são destacados: a) desinteresse, inconveniência e apatia; b) medo; c) desatualização dos dados cadastrais; e d) mudança no quadro de saúde. Com exceção da mudança no quadro de saúde, que de certa forma envolve elementos além do controle, os demais motivos podem ser enquadrados na perspectiva comportamental na medida em que podem ser produtos da própria falha humana, seja no desconhecimento de suas próprias preferências em longo prazo; falta de informação e entendimento sobre os procedimentos envolvidos; ou preguiça, desleixo e esquecimento.

Em primeiro lugar, tratar-se-á da falta de interesse, inconveniência e apatia que pode estar presente em uma parcela dos cadastrados que recusam levar a doação adiante. Conforme Bergstrom (2007), geralmente, quem se cadastra como doador de medula óssea deve acreditar fortemente que sua doação é essencial para salvar uma vida, apresentando sentimentos altruístas mais fortes. Nesse sentido, a lei sancionada pode apresentar um efeito colateral indesejado.

Embora os incentivos da Lei 13.656 não sejam diretamente entregues ao doador cadastrado na forma monetária, há a isenção de pagamentos de taxa de inscrição em concursos públicos para os mesmos. Esse incentivo, então, seria visto como um privilégio que poderia ser um propulsor para os candidatos que estivessem em dúvida quanto à efetuação do cadastro. Mas, tem como consequência ser um chamariz para aqueles que inicialmente não tinha a intenção de se cadastrar - e por consequência efetuar a doação. Assim, a preocupação surge quando iniciativas dessa natureza atraem indivíduos que não apresentam crença intrínseca na voluntariedade e altruísmo, o que criaria a falta de interesse em efetuar a doação caso o indivíduo fosse chamado (SWITER, 2004, p. 1533).

Além disso, a apatia tanto em se cadastrar quanto em efetuar a doação pode estar relacionada com um problema de carona e um problema de difusão de responsabilidade. O número elevado de cadastrados existentes pode levar um candidato em potencial a concluir que "há uma boa chance de que alguém do seu tipo já esteja presente no registro. Se assim for, sua própria contribuição, simplesmente, substituiria a de outro potencial doador registrado" (BERGSTROM et al, 2007, p. 03 - Tradução própria).

É possível fazer um paralelo entre esse "problema de carona" enfrentado com o conceito de difusão de responsabilidade de Darley e Latané (1968). Os autores 
argumentam que, em certas circunstâncias, a necessidade de agir pode ser difundida entre os indivíduos, levando-os a entrar em um estado de inércia com a esperança de que outra pessoa tome a iniciativa em seu lugar. Daí surge a hipótese de que quanto maior o número de espectadores em uma situação de emergências, menor será a probabilidade ou a velocidade de reação (DARLEY; LATANÉ, 1968, p. 378).

Assim, aplicando a difusão de responsabilidade no caso de doação de medula, é possível que alguns indivíduos não se cadastrem para evitar a inconveniência de ter que doar caso sejam chamados e eles se acalentam com a explicação de que outra pessoa estaria mais apta a doar em seu lugar. São essas pessoas que realmente não deveriam se cadastrar, porque não apresentam qualquer intenção em efetuar a doação caso sejam contatadas. O problema é que a Lei 13.656 pode incentivá-las a quebrar a apatia e se dirigir ao centro de sua região para se cadastrar como doador. Mas, como elas foram motivadas visando o privilégio concedido, não haveria qualquer incentivo em longo prazo que os motivassem a efetuar a doação caso solicitados.

Ademais, segundo Switer et al. (2004), o recrutamento do voluntário envolve custos como a retirada do sangue, o envio para a tipagem HLA e a entrada e manutenção dos dados cadastrais, sendo um grande desperdício de recursos saber que o indivíduo se cadastrou sem a intenção de realizar a doação. Assim, é importante esclarecer aos candidatos o comprometimento de longo prazo envolvido na doação e cadastro, a fim de se evitar que a euforia ao se cadastrar seja transformada em apatia no futuro.

Portanto, as recusas diretas provenientes do desinteresse e apatia poderiam ser amenizadas com estratégias que focassem na seleção mais rigorosa dos candidatos para encorajar somente os indivíduos altamente comprometidos com a causa (SWITER, 2004, p. 1534). Switer et al. (2004) argumenta que indivíduos que já estejam engajados em voluntariado médico, como doadores de sangue, devem ser encorajados a se cadastrar ou encorajar aqueles que já se cadastraram a participarem de outras atividades de voluntariado médico -, pois essa é uma forma de se promover o compromisso com a doação de medula e desenvolver um comprometimento psicológico com a doação de medula.

Quando o cadastramento é feito sob pressão social, mais comuns em mutirões ou campanhas em empresas, os doadores podem não apresentar fortes motivações para realizar a doação em comparação com os doadores tradicionais (BUTTERWORTH et al., 1993, p. 1958). Quando a doação solicitada é não parentada, essa motivação deve ser 
ainda mais intensa para diminuir as chances de recusa e tornar a experiência de doação mais positiva (BUTTERWORTH et al., 1993, p. 1958).

Assim, até as formas de recrutamento devem ser arquitetadas para barrar a retenção de indivíduos que apresentem motivações fracas ou que foram guiados por pressão social. Switer et al. (1999) destaca três aspectos importantes na forma como os recrutamentos devem ser feitos: 1) diminuição da dúvida com auxílio de materiais informativos adicionais e disponibilização de tempo para discutir a decisão com profissionais de saúde, amigos e familiares; 2) proteção dos potenciais doadores da pressão social em se registrar; e 3) promoção do compromisso intrínseco de doar, como sugerir que o indivíduo doe sangue também.

Conforme Switer (2004) e Switer et al. (1999), aumentar os padrões de seletividade e o design do recrutamento seriam uma saída para evitar que candidatos com preferências mal definidas sejam realmente admitidos como doadores. Nesse aspecto, a eficiência da lei em questão poderia ser aumentada. Uma vez que a seletividade do cadastro e recrutamento aumentariam, somente os indivíduos que tenham vontade intrínseca de doar conseguiriam se registrar.

No geral, os riscos médicos e psicológicos para os doadores são menos complexos que as avaliações legais e éticas envolvidas (DURBIN, 1988, p. 777). Mas, o medo ainda é um fator muito presente quando os cadastrados recusam fazer a doação. A responsável por isso é a falta de informação e esclarecimento de potenciais riscos. É preciso destacar os efeitos negativos e positivos que o doador pode presenciar ao se submeter ao procedimento.

Uma maneira de explanar os efeitos negativos é explicar as reais consequências que podem acontecer durante e após o processo. Apesar do desconforto, estresse e inconveniências durante o procedimento, a recuperação é total e sem sequelas. É necessário explicá-las para saber se o indivíduo, consciente dos efeitos negativos que sofrerá, gostaria de se cadastrar mesmo assim (BUTTERWORTH et al., 1992, p. 172).

Contudo, quando o transplante é um sucesso, muitas pessoas que se submeteram à doação não parentada relataram se sentir mais úteis, orgulhosos e como se sua vida valesse mais a pena (SIMMONS et al., 1993, p. 285). Há casos em que houve afloramento de uma identidade social, religiosidade, solicitude profissional, desejo de ser um exemplo a ser seguido e sentimento de pertencimento com o grupo de doadores de medula (ibidem, p. 297). Portanto, a forma de se tratar os possíveis doadores que apresentem medo é 
explicar que mesmo que o processo seja custoso e estressante, é possível que a experiência seja muito positiva e edificante.

Por fim, outro aspecto das recusas não é uma recusa per se, mas sim uma falha no contato. Muitos indivíduos se registram e esquecem de atualizar os dados cadastrais. $\mathrm{E}$ não é porque esta é uma tarefa trabalhosa. Para atualizar os dados, basta entrar no site do REDOME e clicar no botão laranja em destaque na página principal escrito "Doador: atualize seu cadastro". Mesmo assim, a desatualização dos dados é preocupante. É preciso então entender por que a atualização não é feita. Um dos possíveis motivos é o esquecimento.

Para esse problema talvez seja útil utilizar lembretes para fidelizar os indivíduos e fazer com que eles se alertem para a importância de manter os dados de contato sempre atualizados. Estratégia que já é adotada pela AMEO (Associação da Medula Óssea). A instituição faz uso de cartões de doadores, cartas de agradecimento, revistas periódicas, além de enviar e-mails de boas-vindas, aniversário e boas festas (AMEO, 2018). Pode parecer banal, mas esses mecanismos de comunicação servem para lembrar que o indivíduo em questão está cadastrado nos centros e que ele deve atualizar seus dados cadastrais se esse for o caso.

Em suma, ressalta-se que o diagnóstico do problema e o desenvolvimento de soluções alternativas apresentados nesta seção são um exercício analítico para exemplificar as novas possibilidades que o estudo do comportamento humano pode proporcionar para as políticas públicas. Desta forma, a ideia central foi mostrar como é essencial investigar os fatores psicológicos que estão por trás da escolha de se cadastrar e de se realizar a doação. É por meio do entendimento dessas particularidades que é possível compreender como o cadastro de doador de medula óssea pode ser incentivado sem que haja efeitos colaterais a fim de diminuir o número de desistências.

\section{CONSIDERAÇÕES FINAIS}

O objetivo deste trabalho foi apresentar a limitação da racionalidade presente nos agentes econômicos e como a compreensão desta é importante para o desenvolvimento de intervenções governamentais mais eficientes. Segundo a teoria comportamental, para neutralizar as possíveis falhas de julgamento presentes, seria mais adequado o uso de políticas públicas que auxiliassem os indivíduos durante um processo de escolha 
(KAHNEMAN, 2012, p. 514). E o apelo do seu uso fica mais evidente quando se devem evitar medidas coercitivas como soluções para o problema diagnosticado.

No caso analisado da Lei 13.656/2018, há a proposta da isenção do pagamento de taxa de inscrição em concursos públicos para os candidatos cadastrados como doadores de medula óssea. É só com um banco de registros rico e variado que se terá chances de encontrar um doador compatível para efetuar o transplante, haja vista que encontrar compatibilidade de medula é raro e demorado. Contudo, a lei se atém somente ao cadastramento, não há nenhum incentivo para o indivíduo, que já tem direito ao benefício assim que se cadastra, de realmente efetuar a doação quando solicitado. E, no Brasil, o número de desistências é alarmante, o que preocupa quem depende da doação, já que uma recusa pode ser letal para o paciente que espera.

Dessa forma, seria necessária a formulação de políticas públicas que barrem um possível aumento nas recusas de doações de medula óssea. As estratégias apresentadas tiveram como intuito exemplificar a utilização dos princípios da economia comportamental em uma situação real, mostrando que a interpretação da situação enfrentada sob uma perspectiva comportamental pode ser eficaz para a formulação de políticas públicas, principalmente quando se tem intenção de evitar medidas coercitivas. Como visto, políticas públicas dessa natureza têm como alicerce a limitação da racionalidade e o processo decisório dos indivíduos. Assim, para que as medidas tenham sucesso, é imprescindível que haja acompanhamento e conhecimento do comportamento efetivo dos envolvidos.

Por isso, trabalhos futuros poderiam focar no avanço de estudos empíricos no que diz respeito à doação de medula óssea no Brasil, compondo mais informações em relação a dados socioeconômicos dos cadastrados e taxas de desistências nacionais ou regionais. Além disso, os órgãos responsáveis brasileiros devem contabilizar consistentemente a recusa nas doações de medula, detectar quais são os principais motivos que levaram o indivíduo a se cadastrar e os fatores relatados para as desistências, a fim de investigar os elementos psicológicos que influenciaram a escolha e recusa. Somente com o monitoramento dessas informações é que é possível desenvolver soluções alternativas focadas na neutralização e minimização dos problemas comportamentais diagnosticados, o que poderia aumentar a eficiência das políticas públicas.

\section{REFERÊNCIAS}


AMEO. Fidelização de doadores. 2018. Disponível em:

<http://ameo.org.br/projetos/fidelizacao-de-doadores-voluntarios-de-medula-ossea/>. Acesso em: 05 de fevereiro de 2021.

ÁVILA, F.; BIANCHI, A. M. Prefácio. In:. Guia de Economia Comportamental e Experimental. São Paulo: EconomiaComportamental.org, p. 13-19, 2015.

ÁVILA, F.; MENEGUIN, F. B. In: ÁVILA, F.; BIANCHI, A. M (Org.). Guia de Economia Comportamental e Experimental. São Paulo: EconomiaComportamental.org, p. 209220, 2015.

BARROS, G. Herbert Simon e o conceito de racionalidade: limites e procedimentos. Revista de Economia Política, v. 30, n. 3, p. 455-472, 2010.

BAUM, William M. Compreender o behaviorismo: ciência comportamento e cultura. 2 ed. Porto Alegre: Editora Artmed, 2005.

BAZERMAN, M. H.; MOORE, D. Processo decisório. 7 ed. Rio de Janeiro: Editora Campus, 2010.

BEAL, R. W.; AKEN, W. G. Gift of good? A contemporary examination of the voluntary and commercial aspects of blood donation. Vox Sang, Amsterdam, v. 63, p. 1-5, 1992.

BERGSTROM, T.; GARRATT, R.; SHEEHAN-CONNOR, D. One Chance in a Million: Altruism and The Bone Marrow Registry, CESifo, Working Paper No. 2090, 2007.

BERNABOU, R.; TIROLE, J. Incentives and Prosocial Behavior. The American Economic Review, v.96, n. 5, p. 1652-1678, 2006.

BRASIL. Decreto-lei n. 13.656, de 30 de abril de 2018. Diário Oficial da União, Brasília, ano CLV, n. 83, seção 1, 2018. Disponível em:

<http://www.planalto.gov.br/ccivil_03/_Ato2015-2018/2018/Lei/L13656.htm>. Acesso em: 04 de fevereiro de 2021.

BUTTERWORTH, V. A. et al. Psychosocial Effects of Unrelated Bone Marrow Donation: Experiences of the National Marrow Donor Program. Blood, v.81, n.7, p. 1947-1959, 1993.

BUTTERWORTH, V. A., SIMMONS, R. G., SCHIMMEL, M. When altruism fails: reactions of unrelated bone marrow donors when the recipient dies. OMEGA, v.26, n.3, p. 161-173, 1992.

CAMERER, C. Behavioral Economics: Reunifying psychology and economics. PNAS, v.96, p. 10575-10577, 1999.

CAMERER, C. F., LOWENSTEIN, G. Behavioral Economics: Past, Present, Future. 2002. Disponível em:

<https://www.researchgate.net/publication/228359684_Behavioral_Economics_Past_Pres ent_Future>. Acesso em: 04 de fevereiro de 2021. 
CARVALHO, M.; CASTILLO-BRANCO, L.; HABIB, J.; GALVAO-CASTRO, B.; PEREIRA, M. HIV antibodies in beggar blood donors in Rio de Janeiro. Proc 4th AIDS Conf., Stockholm, 1988.

CEON-CENTRO DE ONCOLOGIA. Os benefícios para o doador de sangue no Brasil, [2021]. Disponível em: <sanguehttps://oncologiaabc.com.br/os-beneficios-para-o-doadorde-sangue-no-brasil/>. Acesso em 15 de novembro de 2021.

DARLEY, J. M.; LATANÉ, B. Bystander Intervention in Emergencies: Diffusion of Responsibility. Journal of Personality and Social Psychology, v.8, n.4, p. 377-383, 1968.

DATTA, S.; MULLAINATHAN, S. Behavioral Design: A new approach to development policy. Review of Income and Wealth, Series 60, n.1, p. 07-35, 2014.

DURBIN, M. Bone Marrow Transplantation: Economic, Ethical, and Social Issues.

California: Pediatrics, v. 82, n.5, 1988.

ELLINGSEN, T.; JOHANNESSON, M. Generosity. Stockholm: Working Paper Series in Economics and Finance No. 664, 2007.

GRAND, J. L.; NEW, B. Government Paternalism: Nanny State or Helpful Friend? Princeton University Press, 2015.

KAHNEMAN, D. Rápido e Devagar: Duas Formas de Pensar. Rio de Janeiro: Editora Objetiva, 2012.

KAHNEMAN, D. TVERSKY, A. Prospect Theory: An Analysis of Decision under Risk. Econometrica, v.47, n.2, p. 263-292, 1979.

LINDBLOM, C. E. EI Processo de Elaboración de Políticas Públicas. Madrid: MAP _ Ministerio para las Administraciones Públicas, 1991. Colección Estudios, Serie Administración General.

LOEWENSTEIN, G.; ANGNER, E. Methods: Theory. Simple models of psychological phenomena. Carnegie Mellon University, 2006. Disponível em: $<$ https://www.cmu.edu/dietrich/sds/docs/loewenstein/BehavioralEconomics.pdf>. Acesso em: 04 de fevereiro de 2021.

MADRIAN, B. C.; SHEA, D. F. The Power of Suggestion: Inertia in 401(K) Participation and Savings Behavior. National Bureau of Economic Research, 2000. Disponível em: <http://www.nber.org/papers/w7682>. Acesso em: 03 de fevereiro de 2021.

MINISTÉRIO DA SAÚDE. Semana de Mobilização Nacional para Doação de Medula Óssea, 2020. Disponível em: <http://bvsms.saude.gov.br/ultimas-noticias/3379-14-a-2112-semana-de-mobilizacao-nacional-para-doacao-de-medula-ossea>. Acesso em: 02 de fevereiro de 2021.

NELSON, K.; VLAHOV, D.; MARGOLICK, J.; BERNAL, M.; TYLOR, E. Blood and plasma donations among a cohort of intravenous drug users. JAMA, 1990. 
NIZA, C.; MARTEAU, T. M.; TUNG, B. Incentivizing Blood Donation: Systematic Review and Meta-Analysis to Test Titmuss' Hypotheses. Health Psychology, v.32, n.9, p. 941949, 2013.

PILIAVIN, J. A. Why they give the gift of life? A review research on blood donors since 1977. Transfusion, v.30, n.5, p. 444-459, 1990.

REDOME. Nota de esclarecimento do REDOME sobre a isenção da taxa de inscrição em concurso público. [2018]. Disponível em: <http://redome.inca.gov.br/nota-deesclarecimento-redome/>. Acesso em: 02 de fevereiro de 2021.

REDOME. Dados, 2021a Disponível em: <http://redome.inca.gov.br/o-redome/dados/>. Acesso em: 05 de fevereiro de 2021.

REDOME. Como é feita a busca por um doador. [2021b]. Disponível em: $<$ http://redome.inca.gov.br/paciente/como-e-feita-a-busca-por-um-doador/>. Acesso em: 05 de fevereiro de 2021.

SIMON, H. An empirically based microeconomics. Cambridge, UK: Cambridge University Press, 1997.

SIMON, H. Rational Decision Making in Business Organization. American Economic Review, v. 69, n. 4, p. 493-513, 1979.

SIMON, H. Satisficing. In: EATWELL, J.; MILGATE, M.; NEWMAN, P. (eds). The new Palgrave. A dictionary of economics. New York: Palgrave, 1987.

SIMON, H. From substantive to procedural rationality. In: LATSIS, S. (ed.). Method and appraisal in economics. Cambridge: Cambridge University Press, p. 129-148, 1976.

SEPULVEDA, J.; AVILA, C.; DOMINGUEZ, J. Control measures to prevent HIV transmission by blood products in Mexico. Proc 4th AIDS Conf, Stockholm, 1988.

SERVICE, O. et al. EAST: Four simple ways to apply behavioural insights. The Behavioural Insight Team, 2012. Disponível em:

<http://www.behaviouralinsights.co.uk/publications/east-four-simple-ways-to-applybehavioural-insights/>. Acesso em: 03 de fevereiro de 2021.

SIMMONS, R. G., SCHIMMEL, M., BUTTERWORTH, V. A., The Self-Image of Unrelated Bone Marrow Donors. Journal of Health and Social Behavior, v.34, n.4, p. 285-301, 1993.

STOICOV, C. Economia Comportamental Nas Políticas Públicas. São Paulo: Fundação Getúlio Vargas - Escola de Administração de Empresas de São Paulo, 2014. Disponível em: <http://bibliotecadigital.fgv.br/dspace/handle/10438/12435>. Acesso em: 04 de fevereiro de 2021. 
SUSTEIN, C. R. Nudging: Um Guia Breve. In: ÁVILA, F. e BIANCHI, A. M., Guia De Economia Comportamental e Experimental. São Paulo: EconomiaComportamental.org, 2015.

SWITER, G. E., et al. Factors associated with attrition from a national bone marrow registry. Nature, Bone Marrow Transplantation, v.24, p. 313-319, 1999.

SWITER, G. E.; et al. Attrition of Potencial Bone Marrow Donors at Two Key Decision Points Leading to Donation. Transplantation Society, v.77, n.10, p. 1529-1534, 2004.

THALER, R. H.; SUSTEIN, C. R. Nudge: Improving Decisions about Health, Wealth and Happiness. New Haven \& London: Yale University Press, 2008.

THALER, R. H.; SUSTEIN, C. R. Libertarian Paternalism is Not an Oxymoron. Chicago: Working Paper No. 43, 2003.

THALER, R. Toward a Positive Theory of Consumer Choice. Journal of Economic Behavior and Organization, p. 39-60, 1979.

TITMUSS, R. The Gift of Blood. Society, n.35, p. 88-97,1998. (Publicação original: 1971). Disponível em: <https://link.springer.com/content/pdf/10.1007/BF02838132.pdf>. Acesso em: 04 de fevereiro de 2021.

VILLAGRA, A. $\mathbf{4 0 \%}$ dos doadores convocados pelo Hemocentro da Santa Casa para exames confirmatórios desistem da doação ou não são encontrados. AMEO, [2016a]. Disponível em: <http://ameo.org.br/40-dos-doadores-convocados-pelohemocentro-da-santa-casa-para-exames-confirmatorios-desistem-da-doacao-ou-nao-saoencontrados/>. Acesso em: 04 de fevereiro de 2021.

VILLAGRA, A. Recusa do doador e doador não encontrado são principais causas do cancelamento de doadores compatíveis encontrados na Santa Casa de São Paulo. AMEO, [2016b]. Disponível em: <https://ameo.org.br/recusa-do-doador-e-doador-naoencontrado-sao-principais-causas-do-cancelamento-de-doadores-compativeisencontrados-na-santa-casa-de-sao-paulo/>. Acesso em: 04 de fevereiro de 2021.

WHITE, M. D. The Manipulation of Choice: Ethics and Libertarian Paternalism. New York: Palgrave Macmillan, 2013. 